\title{
Baz Ümitvar Koca Fiğ (Vicia narbonensis L.) Hatlarında Tohum Verimi ve İlgili Özelliklerin Belirlenmesi ve GGE Biplot Analiz Yöntemi ile Değerlendirilmesi
}

\author{
Mehmet Salih SAYAR ${ }^{1} \quad$ Yavuz HAN $^{2} \quad$ Mehmet BAŞBAĞ $^{3}$ \\ ${ }^{1}$ Dicle Üniversitesi Bismil MYO Bitkisel ve Hayvansal Üretim Bölümü, Bismil, Diyarbakır \\ ${ }^{2}$ GAP Uluslararası Tarımsal Araştırma ve Eğitim Merkezi Müdürlüğü, Diyarbakır. \\ ${ }^{3}$ Dicle Üniversitesi Ziraat Fakültesi Tarla Bitkileri Bölümü, Diyarbakır \\ $\triangle$ : msalihsayar@hotmail.com
}

Geliş (Received): 02.11.2017

Kabul (Accepted): 15.12.2017

\begin{abstract}
ÖZET: Bu çalışma, bazı ümitvar koca fiğ (Vicia narbonensis L.) hatlarının Güneydoğu Anadolu Bölgesi ekolojik koşullarında tohum verimi ile tohum verimi üzerinde etkili bazı önemli verim unsurlarının saptanması amacıyla yürütülmüştür. Bu amaçla; 2008-09, 2009-10 ve 2010-11 ekim sezonlarında 3 yıl süreyle Diyarbakır GAP Uluslararası Tarımsal Araştırma ve Eğitim Merkezi Müdürlüğü deneme arazisinde, tesadüf blokları deneme desenine göre üç tekrarlamalı olarak tarla denemeleri kışlık olarak yürütülmüştür. Araştırmada denemenin yürütüldüğ̈ yıllar ve genotipler arasında incelenen özellikler aşağıdaki gibi değişim göstermiştir. Tohum verimi 131.3-346.6 $\mathrm{kg} \mathrm{da}^{-1}$, biyolojik verim 369.8-971.6 $\mathrm{kg} \mathrm{da}^{-1}$, hasat indeksi \%24.3-40.4, saman (kes) verimi 238.4-625.1 $\mathrm{kg} \mathrm{da}^{-1}$, bin dane ağıllı̆̆ 113.7-204.0 g, bitkide bakla sayısı 10.4-19.7 adet, baklada tane sayısı 4.40-6.20 adet ve fizyolojik olum gün sayısı 185.6-206.3 gün. Araştırmada tohum verimi, biyolojik verim, hasat indeksi, saman verimi ve bitkide bakla sayısı özellikleri bakımından genotip $\times$ yll interaksiyonu önemli bulunurken $(\mathrm{P}<0.05)$, bin dane ağıllığı, baklada tohum sayısı ve fizyolojik olgunlaşma gün sayısı özellikleri bakımından ise önemsiz bulunmuştur. GGE biplot analiz yöntemi ile yapılan analiz sonucuna göre; tüm özellikler birlikte dikkate alındığında, deneme yıllarının istatistiki olarak birbirlerinden farklı olduğu, incelenen sekiz özelliğin ise 3 gruba ayrıldı̆̆ı, tohum verimi, biyolojik verim, saman verimi, bitkide bakla sayısı ve hasat indeksi özelliklerinin aynı grupta olduğu ve bu özellikler bakımından IFVN 565-SEL 2380 (G2) ve IFVN 567-SEL 2382 (G4) hatlarının daha üstün oldukları belirlenmiştir.
\end{abstract}

Anahtar Kelimeler: Koca Fiğ (Vicia narbonensis L.), genotip $\times$ yıl interaksiyonu, tohum verimi, verim kompenentleri, GGE Biplot analizi.

\section{Determining Seed Yield and Yield Components of Some Promising Narbon Vetch (Vicia narbonensis L.) Lines and Assessments Using GGE Biplot Analysis Method}

\begin{abstract}
This study was conducted to determine seed yield and yield components in promising narbon vetch lines (Vicia narbonensis L.) under the ecological conditions of Southeastern Anatolia region of Turkey. For this reason, field trials were performed in the research areas of GAP International Agricultural Research and Training Center (GAP IARTC) in Diyarbakir, Turkey during the 2008-09, 2009-10 and 2010-11 growing seasons with winter sowings. Experiments were established according to randomized blocks design with three replications. Among growing seasons and genotypes the investigated traits had ranges as follows: Seed yield $-131.3-346.6 \mathrm{~kg} \mathrm{da}^{-1}$, biological yield - 369.8-971.6 $\mathrm{kg} \mathrm{da}^{-1}$, harvest index - \%24.3-40.4\%, straw yield -238.4-625.1 $\mathrm{kg} \mathrm{da}^{-1}, 1000$ seed weight $-113.7-204.0 \mathrm{~g}$, the number of pods per plant $-10.4-19.7$ pod plant ${ }^{-1}$, the number of seeds per pod -4.40 -

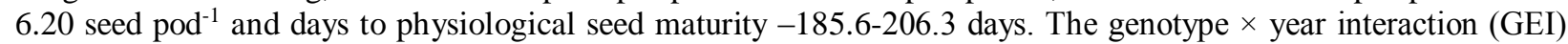
was found highly statistically significant $(\mathrm{P}<0.01)$ for seed yield, biological yield, harvest index, straw yield and the number of pods per plant traits. However, GEI was found as non-significant $(\mathrm{P}>0.05)$ for 1000 seed weight, the number of seeds per pod and days to physiological seed maturity traits. Results of the GGE biplot analysis revealed that the three growing seasons were found different each other in terms of the investigated traits. Additionally; the investigated eight traits were divided into three groups, seed yield, biological yield, straw yield, the number of pods per plant and harvest index took part in the same group. And IFVN 565-SEL 2380 (G2) ve IFVN 567-SEL 2382 (G4) were found superior than the other genotypes for these important five traits.

Key words: Narbon vetch (Vicia narbonensis L.), genotype $\times$ year interaction, seed yield, yield components, GGE biplot analysis
\end{abstract}

\section{GíRiş}

Fiğ türleri içerisinde kışa dayanıklılı̆g 1 yüksek olan koca fiğ, yeşil ot, kuru ot, silaj, dane yemi ve yeşil gübre amaciyla yetiştirilebilmektedir (Gençkan, 1983; Sağlamtimur ve ark., 1988, Manga ve ark., 1995, Açıkgöz, 2001). Ancak kuru otunun sert, saplarının kalın ve sap/yaprak oranın fazla olması bu bitkiyi daha çok yeşil gübre, silo yemi ve tohum üretimi için yetiştirmeyi zorunlu kılmaktadır. Koca fiğ Güneydoğu Anadolu Bölgesinin doğal vejetasyonlarında sıkça rastlanılan bir türdür (Sayar ve ark., 2015). Ve dünyanın kurak ve yarı kurak alanlarında yetişebilen ender 
bitkilerden birisidir (Abd-El Moneim ve ark., 1990; Abd-El Moneim, 1992). Ülkemizde nadasın yapıldığı geçit bölgelerinde koca fiğin yer aldığı ekim nöbetlerinde başarılı sonuçlar alınmıştır (Kalayc1, 1981).

Genotiplerin geniş alanlarda üretimlerine geçilmeden önce değişik yıllar ve lokasyonlarda denenerek genotip $\times$ çevre interaksiyonlarının belirlenmesi büyük önem arz etmektedir (Açıkgöz ve ark., 2009; Sayar ve ark., 2013). Genotip × çevre interaksiyonlarının belirlenmesinde en etkili yöntemlerden biri de GGE (Genotype $\times$ GenotypeEnvironment) biplot analiz yöntemidir. $\mathrm{Bu}$ analiz yöntemi ile oluşturulan grafikler son zamanlarda bitki ıslahı konusunda, değişik tarımsal ürünlerde çalışan pek çok araştırıcı tarafından kullanılmıştır (Yan ve ark., 2000; İlker ve ark., 2009; Kılıç ve ark., 2012; Kendal ve Doğan 2015; Kendal ve Sayar 2016; Sayar ve Han 2016; Kendal ve Aktaş, 2016). Bu analiz yönteminin araştırıcılar tarafindan yaygın bir şekilde tercih edilmesinin en önemli nedenleri arasında, genotiplerin farklı çevrelerle olan interaksiyonlarının basit ve anlaşılır bir biçimde ortaya konulabilmesi, genotiplere ait birden fazla özelliğin grafiksel olarak bu analiz yönteminde gösterilebilmesi, gerek genotip ve gerekse özellikler arasındaki ilişkileri görsel olarak karşılaştırmaya olanak sağlaması gösterilebilir (Sayar ve Han, 2015).

$\mathrm{Bu}$ araştırma, bazı ümitvar koca (Vicia narbonensis L.) fiğ hatlarının Güneydoğu Anadolu bölgesi ekolojik koşullarındaki tohum verimi ve verim kompenentlerini belirlemek amacıyla yürütülmüştür. Ayrıca koca fiğ hatlarının incelenen bütün özellikleri dikkate alındığında genotip $\times$ yıl interaksiyonları ile incelenen özelliklerin genotiplerle olan ilişkisi GGE Biplot analiz yöntemi kullanılarak farklı şekillerle ortaya konulmuş ve değerlendirilmiştir.

\section{MATERYAL ve YÖNTEM}

Bu çalışma 2008-2009, 2009-2010 ve 2010-2011 yetiştirme sezonlarında, Diyarbakır GAP Uluslararası Tarımsal Araştırma ve Eğitim Merkezi Müdürlüğü

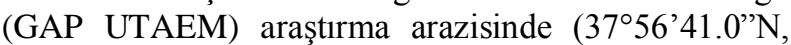
$\left.40^{\circ} 15^{\prime} 16.8^{\prime} \mathrm{E}\right)$, yağışa dayalı şartlarda, kışlık olarak yürütülmüştür.

Araştırmada daha önce ICARDA'dan (International Center for Agricultural Research in Dry Areas, Aleppo, Syria) temin edilen ve GAP UTAEM'de yürütülen denemelerde ümitvar görülen IFVN 564 Sel 2379 (G1), IFVN 565 Sel 2380 (G2), IFVN 575 Sel 2389 (G3), IFVN 567 Sel 2382 (G4), IFVN 116 Sel 2461 (G5), IFVN 562 Sel 2470 (G6) koca fiğ (Vicia narbonensis L.) hatlarıyla ile kontrol çeşit olarak Ankara Tarla Bitkileri Merkez Araştırma Enstitüsü tarafindan tescil edilen Tarman-2002 (G7) koca fiğ çeşidi kullanılmıştır.

Yaklaşık 610 metre rakım değerine sahip deneme yerinin üst $30 \mathrm{~cm}$ derinliğinden alınan toprak örneklerinde yapılan analizler sonucunda; toprak bünyesinin killi-tınlı olduğu, ayrıca toplam tuz \% 0055, $\mathrm{pH}$ 7.67, kireç \% 12.54, organik madde \% 1.60, yarayışlı fosfor $\left(\mathrm{P}_{2} \mathrm{O}_{5}\right) 2.85 \mathrm{~kg} / \mathrm{da}$, potas $\left(\mathrm{K}_{2} \mathrm{O}\right) 48 \mathrm{~kg} / \mathrm{da}$ olarak saptanmıştır. Diyarbakır Meteoroloji Bölge Müdürlüğü verilerine göre; deneme yerinin uzun yıllar yıllık sicaklık değerleri ortalamasının $12.7{ }^{\circ} \mathrm{C}$, denemelerin yürütüldüğü 2008-09 ekim sezonunda 12.4 ${ }^{\circ} \mathrm{C}$ ve $2009-10$ ekim sezonunda $14.3{ }^{\circ} \mathrm{C}$ ve $2010-11$ ekim sezonunda ise $13.6{ }^{\circ} \mathrm{C}$ olmuştur. Uzun yıllar yıllık nisbi nem ortalaması \%59.4, 2008-09 ekim sezonunda $\% 56.9$, 2009-10 yilında \%59.5 ve 2010-11 ekim sezonunda \%57.4 olmuştur. Diyarbakır ilinde uzun yıllar ortalaması yıllık düşen toplam yağış miktarı 479.8 mm iken, denemelerin yürütüldüğü 2008-09 ekim sezonunda $455 \mathrm{~mm}, 2009-10$ ekim sezonunda $517.9 \mathrm{~mm}$ ve 2010-11 ekim sezonunda ise $553.0 \mathrm{~mm}$ olarak kaydedilmiştir.

Denemeler her üç yılda da tesadüf blokları deneme desenine göre 3 tekerrürlü olarak kurulmuştur. Ekimde parsel büyüklüğü $7.2 \mathrm{~m}^{2}$ olmuştur (6 m sira uzunluğu x 6 sira sayıs1 x $20 \mathrm{~cm}$ sira arasi mesafe). Deneme ekimleri 1. yılda 14 Kasım 2008 tarihinde, 2. y1lda 20 Kasım 2009 ve 3. yılda ise 11 Kasim 2010 tarihinde tavlı toprağa deneme mibzeri ile yapılmıştır. Araştırmada metre kareye 100 tohum düşecek şekilde ekim normu ayarlanmıştır (Anonim, 2001). Ekimle beraber dekara $2.7 \mathrm{~kg}$ saf azot ve $6.9 \mathrm{~kg}$ saf fosfor olacak şekilde taban gübrelemesi yapılmıştır. Denemelerin yabanci ot mücadelesi her 3 yilda da zamanında elle yapılmıştır.

Deneme parselleri fizyolojik olum döneminde biyolojik verim ve tohum ile ilgili gözlemleri almak için hasat edilmiştir. Araştırmada incelenen özellikler, Anonim (2001)'de belirlenen yöntemlerle saptanmıştır. Araştırma sonucunda elde edilen üç yıllık veriler birleştirilerek varyans analizleri JMP 5.0.1 istatistik paket programında (SAS Institute, 2002) yapılmış, ortalamalar arası farklılı, LSD ( $\%$ 5 $)$ çoklu karşılaştırma testine (Steel ve Torrie, 1980) göre belirlenmiştir. Araştırmada GGE Biplot analizleri ve grafikleri Genstat-14.0 istatistik paket programında (VSN International, 2011) Yan ve ark (2000) ile Yan ve Kang 2003'te belirtilen yöntemler dikkate alınarak belirlenmiştir. Grafik değerlendirme ve yorumları ise yorumlamaları ise son y1llarda GGE biplot analizi ilgili yayın yapan araştırıcılara göre yapılmıştır (Yan ve Kang, 2003; Yan ve Tinker, 2006; İlker ve ark., 2009; Sayar ve Han, 2015; Kendal ve Sayar 2016; Sayar ve Han, 2016; Kendal ve ark., 2016).

\section{BULGULAR ve TARTIŞMA}

Araştırmada incelenen özelliklerin yll ve genotip ortalamaları ile genotip $\times$ yıl interaksiyonları Çizelge 1 , Çizelge 2, Çizelge 3 ve Çizelge 4'de verilmiştir. İlgili çizelgeler incelendiğinde; bitkide bakla sayısı (BBS) özelliği bakımndan yıllar arasında istatistiki olarak önemli fark bulunmazken, diğer incelenen 7 özellik bakımından yıllar arasındaki fark 0.01 düzeyinde önemli bulunmuştur. Üç yıllık birleştirilmiş ortalamalar dikkate alındığında koca fiğ genotipleri arasında tohum verimi (TV), biyolojik verim (BV), saman (kes) verimi (SV), bin tane ağırlığı (BTA) ve fizyolojik olum gün 
sayıs1 (FOG) özellikleri bakımından çok önemli farklılıklar bulunurken $(\mathrm{P}<0.01)$, hasat indeksi $(\mathrm{HI})$, bitkide bakla sayısı (BBS) ve baklada tane sayısı (BTS) özellikleri bakımından ise genotipler arasında istatistiki olarak önemli fark bulunmamıştır. Aynı çizelgelerden genotip $\times$ yıl interaksiyonları incelendiğinde; tohum verimi, biyolojik verim, saman (kes) verimi ve bitkide bakla sayısı özellikleri için 0.01 düzeyinde, hasat indeksi özelliği için ise 0.05 düzeyinde istatistiki olarak genotip $\times$ yıl interaksiyonu önemli bulunmuştur. Bu özelikler bakımından genotip $\times$ y1l interaksiyonlarının önemli bulunması; yıllar arasında genellikle iklimsel farklılıklardan kaynaklanan çevre değişiklerinin, genotiplerin sıralamalarında önemli derece etki ettiğini göstermektedir. Bin tane ağırlığı, bitkide bakla sayısı ve fizyolojik olum gün sayısı özellikleri için genotip $\times$ yıl interaksiyonu önemsiz bulunmuştur. $\mathrm{Bu}$ durum yıllar arasında oluşan çevresel farklılıkların, bu özelliklerin genotip sıralamasına önemli bir şekilde etki etmediğini gösterir.

Araştırmada denemenin yürütüldüğü yıllar ve genotipler arasında tohum verimi $131.3 \mathrm{~kg} \mathrm{da}^{-1}$ ile 346.6 $\mathrm{kg} \mathrm{da}^{-1}$, biyolojik verim ise $369.8 \mathrm{~kg} \mathrm{da}^{-1}$ ile $971.6 \mathrm{~kg} \mathrm{da}^{-}$
${ }^{1}$ arasında değişim göstermiştir. Üç yıllık ortalamalara göre her iki özellik bakımından denemelerde kullanılan tüm ümitvar koca fiğ hatları kontrol çeşidi Tarman2002'den daha üstün bulunmuştur. Bununla beraber, G2, G4 ve G6 koca fiğ hatları istatiksel olarak diğer genotiplerden biyolojik ve tohum verimi özellikleri bakımından daha üstün bulunmuştur (Çizelge 1). Araştırmada tohum verimine ilişkin saptamış olduğumuz değerler bir çok araştırmacının bulgularıyla tam uyum gösterirken (Sabancı ve ark., 1996; Balabanlı, 1998; Başbağ ve Gül, 2004; Başbağ ve ark., 2015), Sabancı ve ark. (1998)'nın koca fiğde saptamıs olduğu tohum verim değerleriyle (317-582 $\left.\mathrm{kg} \mathrm{da}^{-1}\right) \mathrm{k1smen}$ uyumlu, Çeçen ve ark. (2005)'nın (535 kg da-1) bulgularından daha düşük bulunmuştur. Bulgular arasındaki bu farklılığın nedeni olarak; denemelerin yürütüldüğü ekolojilerin ve denemelerde kullanılan genotiplerin farklı olması gösterilebilir. Araştırmada koca fiğ genotiplerinde biyolojik verim özelliğine ilișkin saptamış olduğumuz bulgular Balabanlı (1998)'nın koca fiğde saptamış olduğu biyolojik verim değerleri (559.7$801.8 \mathrm{~kg} \mathrm{da}^{-1}$ ) ile tam uyumludur.

Çizelge 1. Koca fiğ hatlarında tohum verimi, biyolojik verim özelliklerine ait değerler ve oluşan gruplar ${ }^{+}$

\begin{tabular}{|c|c|c|c|c|c|c|c|c|}
\hline \multirow{3}{*}{ Genotipler } & \multicolumn{4}{|c|}{ Tohum Verimi $\left(\mathrm{kg} \mathrm{da}^{-1}\right)$} & \multicolumn{4}{|c|}{ Biyolojik Verim $\left(\mathrm{kg} \mathrm{da}^{-1}\right)$} \\
\hline & \multicolumn{3}{|c|}{ Yillar } & \multirow{2}{*}{ Ortalama } & \multicolumn{3}{|c|}{ Yillar } & \multirow{2}{*}{ Ortalama } \\
\hline & 2008-09 & $2009-10$ & $2010-11$ & & 2008-09 & $2009-10$ & $2010-11$ & \\
\hline G1- IFVN 564-Sel 2379 & 277.0 b-e & $265.8 \mathrm{e}$ & 289.0 b-e & 277.3 b-c & 861.5 b-d & $687.1 \mathrm{f}$ & $826.1 \quad b-d$ & $791.6 \mathrm{~b}$ \\
\hline G2- IFVN 565-Sel 2380 & 319.0 a-d & 304.8 a-e & 324.3 a-b & $316.0 \mathrm{a}$ & 894.8 a-c & 849.2 b-d & 835.6 b-d & 859.8 a \\
\hline G3- IFVN 575-Sel 2389 & 292.3 b-e & $163.6 \mathrm{f}-\mathrm{g}$ & $270.9 \mathrm{e}$ & 242.3 d-e & $818.2 \mathrm{c}-\mathrm{d}$ & $406.3 \mathrm{~g}$ & $807.2 \mathrm{c}-\mathrm{d}$ & $677.2 \mathrm{c}$ \\
\hline G4- IFVN 567-Sel 2382 & 346.6 a & 309.1 a-e & 292.6 b-e & 316.1 a & 971.6 a & 777.1 d-f & 824.4 b-d & 857.7 a \\
\hline G5- IFVN 116-Sel 2461 & $191.0 \mathrm{f}$ & $266.3 \mathrm{e}$ & 304.0 a-e & $253.7 \mathrm{c}-\mathrm{d}$ & 784.9 d-e & 697.9 e-f & 856.7 b-d & $779.8 \mathrm{~b}$ \\
\hline G6- IFVN 562-Sel 2470 & 307.9 a-e & $323.0 \mathrm{a}-\mathrm{c}$ & 273.4 d-e & 301.4 a-b & 916.7 a-b & $798.3 \mathrm{~d}$ & 786.7 d-e & 833.9 a-b \\
\hline G7- TARMAN-2002 & 275.9 c-e & $131.3 \mathrm{~g}$ & $264.3 \mathrm{e}$ & $223.8 \mathrm{e}$ & $688.3 \mathrm{f}$ & $369.8 \mathrm{~g}$ & 774.4 d-f & $610.8 \mathrm{~d}$ \\
\hline Ortalama & 287.1 a & $252.0 \mathrm{~b}$ & 288.4 a & 288.4 & 848.0 a & $655.1 \mathrm{~b}$ & 815.9 a & 773.0 \\
\hline $\mathrm{CV}(\%)$ & \multicolumn{4}{|c|}{10.37} & \multicolumn{4}{|c|}{11.35} \\
\hline \multicolumn{9}{|l|}{ LSD (0.05) } \\
\hline Yillar & \multicolumn{4}{|c|}{$17.84 * *$} & \multicolumn{4}{|c|}{$35.43^{* *}$} \\
\hline Genotipler & \multicolumn{4}{|c|}{$27.25 * *$} & \multicolumn{4}{|c|}{$54.14 * *$} \\
\hline Genotip $\times$ yll & \multicolumn{4}{|c|}{$47.19 * *$} & \multicolumn{4}{|c|}{$93.77 * *$} \\
\hline
\end{tabular}

+, aynı sütun içerisinde benzer harf grubu ile gösterilen ortalamalar, LSD (\% 5)'e göre farklı değildir; *, \% 5 düzeyinde önemli; **, \% 1 düzeyinde önemli; ÖD, önemli değildir.

Koca fiğ genotiplerinde hasat indeksi değerleri yıllar ve genotipler arasinda \%24.33 ile \%40.45 arasinda, saman (kes) verimi değerleri ise $238.4 \mathrm{~kg} \mathrm{da}^{-1}$ ile 625.1 $\mathrm{kg} \mathrm{da}^{-1}$ arasında değişim göstermiştir. Genotiplerin bu özellikler bakımından 3 yıllık ortalamalarına bakıldığında ise; hasat indeksi özelliğinde genotipler arasında istatiksel olarak önemli farklılık görülmezken, saman (kes) verimi özelliğinde ise, G3 hatt1 ve Tarman2002 (G7) çeșidi dışındaki genotiplerin aynı istatistiki grubu paylaştıkları görülmektedir (Çizelge 2). Bulgularımızla benzer olarak koca fiğde hasat indeksinin \%22.49 ile \%39.87 arasında değișim gösterdiği bildirilmektedir (Uzunmehmetoğlu ve Kendir 2006; Başbağ ve ark., 2015). 
Çizelge 2. Koca fiğ hatlarında hasat indeksi ve saman (kes) verimi özelliklerine ait değerler ve oluşan gruplar ${ }^{+}$

\begin{tabular}{|c|c|c|c|c|c|c|c|c|c|c|c|c|}
\hline \multirow{3}{*}{ Genotipler } & \multicolumn{7}{|c|}{ Hasat İndeksi (\%) } & \multicolumn{5}{|c|}{ Saman (Kes) Verimi $\left(\mathrm{kg} \mathrm{da}^{-1}\right)$} \\
\hline & \multicolumn{6}{|c|}{ Yillar } & \multirow{2}{*}{ Ortalama } & \multicolumn{4}{|c|}{ Yillar } & \multirow{2}{*}{ Ortalama } \\
\hline & 2008 & & $2009-$ & & 2010 & & & 2008 & & $2009-10$ & $2010-11$ & \\
\hline G1- IFVN 564-Sel 2379 & 32.22 & $\mathrm{c}$ & 38.70 & $a-b$ & 35.11 & $a-c$ & 35.34 & 584.5 & $a-c$ & $421.3 \mathrm{f}-\mathrm{g}$ & 537.1 a-d & 514.3 \\
\hline G2- IFVN 565-Sel 2380 & 36.00 & $a-c$ & 35.88 & $a-c$ & 38.85 & $a-b$ & 36.91 & 575.8 & $a-c$ & 544.4 a-d & $511.2 \mathrm{c}-\mathrm{f}$ & 543.8 a \\
\hline G3- IFVN 575-Sel 2389 & 35.97 & $a-c$ & 40.20 & a & 33.35 & $b-c$ & 36.51 & 525.9 & b-d & $242.7 \mathrm{~h}$ & 536.3 a-d & $435.0 \mathrm{~b}$ \\
\hline G4- IFVN 567-Sel 2382 & 35.67 & $a-c$ & 39.95 & a & 35.77 & $a-c$ & 37.13 & 625.1 & $\mathrm{a}$ & $468.0 \mathrm{~d}-\mathrm{g}$ & 531.9 b-d & 541.6 a \\
\hline G5- IFVN 116-Sel 2461 & 24.33 & $\mathrm{~d}$ & 38.10 & $a-c$ & 35.58 & $a-c$ & 32.67 & 593.9 & $a-c$ & $431.7 \quad$ e-g & 552.7 a-d & $526.1 \mathrm{a}$ \\
\hline G6- IFVN 562-Sel 2470 & 33.64 & $b-c$ & 40.45 & a & 34.81 & $a-c$ & 36.30 & 608.8 & $a-b$ & $475.3 \mathrm{~d}-\mathrm{g}$ & $513.2 \mathrm{c}-\mathrm{e}$ & $532.5 \mathrm{a}$ \\
\hline G7- TARMAN-2002 & 40.35 & $\mathrm{a}$ & 35.45 & $a-c$ & 34.65 & $a-c$ & 36.82 & 412.4 & $\mathrm{~g}$ & $238.4 \mathrm{~h}$ & $510.1 \mathrm{c}-\mathrm{f}$ & $387.0 \mathrm{~b}$ \\
\hline Ortalama & 34.03 & $\mathrm{~b}$ & 38.39 & $\mathrm{a}$ & 35.45 & $\mathrm{~b}$ & 35.95 & 560.9 & $\mathrm{a}$ & $403.1 \quad \mathrm{~b}$ & 527.5 a-d & 497.2 \\
\hline $\mathrm{CV}(\%)$ & \multicolumn{7}{|c|}{10.45} & \multicolumn{5}{|c|}{10.96} \\
\hline \multicolumn{13}{|l|}{ LSD (0.05) } \\
\hline Yillar & \multicolumn{7}{|c|}{$2.34 * *$} & \multicolumn{5}{|c|}{$33.94 * *$} \\
\hline Genotipler & \multicolumn{7}{|c|}{ ÖD } & \multicolumn{5}{|c|}{$51.83^{* *}$} \\
\hline Genotip $\times$ yll & \multicolumn{7}{|c|}{$6.20^{*}$} & \multicolumn{5}{|c|}{$89.81 * *$} \\
\hline
\end{tabular}

+, aynı sütun içerisinde benzer harf grubu ile gösterilen ortalamalar, LSD (\% 5)'e göre farklı değildir; *, \% 5 düzeyinde önemli; **, \% 1 düzeyinde önemli; ÖD, önemli değildir.

Çizelge 3. Koca fiğ hatlarında bin tane ağırlığı ve bitkide bakla sayısı özelliklerine ait değerler ve oluşan gruplar ${ }^{+}$

\begin{tabular}{|c|c|c|c|c|c|c|c|c|}
\hline \multirow{3}{*}{ Genotipler } & \multicolumn{4}{|c|}{ Bin Tane Ağırlığı (g) } & \multicolumn{4}{|c|}{ Bitkide Bakla Sayısı (adet bitki ${ }^{-1}$ ) } \\
\hline & \multicolumn{3}{|c|}{ Yillar } & \multirow{2}{*}{ Ortalama } & \multicolumn{3}{|c|}{ Yillar } & \multirow{2}{*}{ Ortalama } \\
\hline & 2008-09 & $2009-10$ & 2010-11 & & 2008-09 & $2009-10$ & 2010-11 & \\
\hline G1- IFVN 564-Sel 2379 & 126.63 & 161.33 & 147.00 & $144.99 \mathrm{~d}$ & $12.64 \mathrm{~d}-1$ & 10.60 g-1 & $14.27 \mathrm{c}-1$ & 12.50 \\
\hline G2- IFVN 565-Sel 2380 & 111.73 & 133.00 & 134.58 & $126.44 \mathrm{e}$ & $17.24 \mathrm{a}-\mathrm{c}$ & $11.93 \mathrm{f}-1$ & $18.67 \mathrm{a}-\mathrm{b}$ & 15.95 \\
\hline G3- IFVN 575-Sel 2389 & 166.23 & 201.08 & 194.25 & $187.19 \mathrm{a}$ & 16.80 a-d & 16.07 a-e & $10.40 \quad 1$ & 14.42 \\
\hline G4- IFVN 567-Sel 2382 & 139.40 & 169.00 & 153.67 & $154.02 \mathrm{c}$ & 16.76 a-d & $14.60 \mathrm{~b}-1$ & $14.93 \mathrm{~b}-\mathrm{g}$ & 15.43 \\
\hline G5- IFVN 116-Sel 2461 & 126.73 & 163.92 & 153.02 & $147.89 \mathrm{c}-\mathrm{d}$ & $14.16 \mathrm{c}-1$ & $19.73 \mathrm{a}$ & $12.27 \mathrm{e}-1$ & 15.39 \\
\hline G6- IFVN 562-Sel 2470 & 153.97 & 177.08 & 161.17 & $164.07 \mathrm{~b}$ & $14.88 \mathrm{~b}-\mathrm{h}$ & 18.47 a-c & $11.73 \mathrm{f}-1$ & 15.03 \\
\hline G7- TARMAN-2002 & 185.53 & 204.00 & 194.92 & $194.82 \mathrm{a}$ & 17.00 a-d & 10.47 h-1 & 15.40 a-f & 14.29 \\
\hline Ortalama & $144.32 \mathrm{c}$ & $172.77 \quad b$ & $162.66 \mathrm{a}$ & 159.92 & 15.64 & 14.55 & 13.95 & 14.71 \\
\hline $\mathrm{CV}(\%)$ & \multicolumn{4}{|c|}{5.43} & \multicolumn{4}{|c|}{8.57} \\
\hline \multicolumn{9}{|l|}{ LSD (0.05) } \\
\hline Yillar & \multicolumn{4}{|c|}{$5.39 * *$} & \multicolumn{4}{|c|}{ ÖD } \\
\hline Genotipler & \multicolumn{4}{|c|}{$8.26 * *$} & \multicolumn{4}{|c|}{ ÖD } \\
\hline Genotip $\times$ yll & \multicolumn{4}{|c|}{ ÖD } & \multicolumn{4}{|c|}{$4.42 * *$} \\
\hline
\end{tabular}

+, aynı sütun içerisinde benzer harf grubu ile gösterilen ortalamalar, LSD (\% 5)'e göre farklı değildir; *, \% 5 düzeyinde önemli; **, \% 1 düzeyinde önemli; ÖD, önemli değildir.

Koca fiğ genotiplerinde bin tane ağırlıkları yıllar ve genotipler arasinda $111.73 \mathrm{~g}$ ile $204.0 \mathrm{~g}$ arasinda değişim göstermiştir. Üç yıllık ortalamalar dikkate alındığında en yüksek bin tane ağırlı̆̆ı G3 hattı (187.19 g) ile Tarman-2002 çeşidinde (194.82 g) saptanırken, en düşük bin tane ağırlığı ise G2 hattında $(126.44 \mathrm{~g})$ saptanmıştır (Çizelge 3). Araştırmada koca fiğ genotiplerinde saptamış olduğumuz bin tane ağılıkları, Başbağ ve Gül (2004) (133.9-205.5 g) ile Bucak (2008)'in (125.7-241.4 g) bulgulariyla tam uyum gösterirken, Uzunmehmetoğlu ve Kendir (2006) (150.67-238.00 g), İptaş ve Karadağ (2009) (171.4318.8 g) ile Nizam ve ark. (2011)'nın (173.83 - 239.09 g) bulgularıyla kısmen uyumlu ve düşük, Başbağ ve ark. (2015)'nın (219.9 g) bulgularından ise düşük bulunmuştur. Koca fiğ genotiplerinde bitkide bakla sayılar1 y1llar ve genotipler arasinda 10.47 adet ile 19.73 adet arasında değişim göstermiştir. Üç yıllık ortalamalara göre bitkide bakla sayısı özelliği bakımından genotipler arasında önemli farklılık bulunmamıştır (Çizelge 3). Araştırmada koca fiğ genotiplerinde saptanılan bitkide bakla sayıları; İptaş ve ark. (1996) (11.0-18.8 adet) ve Büyükburç ve İptaş (2001)'in (11.6-17.0 adet) bulgulariyla tam uyumlu, Türk ve ark. (2004) (9.1-15.1 adet), Uzunmehmetoğlu ve Kendir (2006) (18.00-20.33 adet) ve Orak ve Nizam (2009) (10.97-20.06 adet) Başbağ ve ark. (2015)'nın ( 9.73 adet)bulgularına ise çok yakın bulunmuştur.

Araştırmada koca fiğ genotiplerinde genotipler ve yillar arasinda baklada tane sayiları 4.40 adet ile 6.20 adet arasında değişim göstermiştir. Üç yıllık genotip ortalamaları dikkate alındığında baklada tane sayısı özelliği bakımından genotipler arasında istatiksel olarak önemli bir farklılık saptanmamıştır (Çizelge 4). Araştırmada tespit edilen baklada tane sayıları; Bucak (2008) (4.28-5.20 adet) ve Başbağ ve ark. (2015)'nın (4.96 adet) bulgularıly tam uyum gösterirken, İptaş ve ark. (1996) (3.7-4.5 adet), Büyükburç ve İptaş (2001)(3.9-4.5 adet), Türk ve ark. (2004) (3.3-4.1 adet) ve Uzunmehmetoğlu ve Kendir (2006)'in (3.67-5.33 adet) bulgularıyla kısmen uyumlu ve yüksek bulunmuştur. 
Çizelge 4. Koca fiğ hatlarında baklada tane sayısı ve fizyolojik olum gün sayısı özelliklerine ait değerler ve oluşan gruplar ${ }^{+}$

\begin{tabular}{|c|c|c|c|c|c|c|c|c|}
\hline \multirow{3}{*}{ Genotipler } & \multicolumn{4}{|c|}{ Baklada Tane Sayısı (adet) } & \multicolumn{4}{|c|}{ Fizyolojik Olum Gün Sayısı (gün) } \\
\hline & \multicolumn{3}{|c|}{ Yillar } & \multirow{2}{*}{ Ortalama } & \multicolumn{3}{|c|}{ Yillar } & \multirow{2}{*}{ Ortalama } \\
\hline & 2008-09 & $2009-10$ & 2010-11 & & 2008-09 & $2009-10$ & $0 \quad 2010-11$ & \\
\hline G1- IFVN 564-Sel 2379 & 4.72 & 6.13 & 5.20 & 5.35 & 197.17 & 187.00 & 203.67 & $195.94 \mathrm{c}$ \\
\hline G2- IFVN 565-Sel 2380 & 5.15 & 5.60 & 5.13 & 5.29 & 199.17 & 188.33 & 205.00 & $197.50 \mathrm{a}-\mathrm{b}$ \\
\hline G3- IFVN 575-Sel 2389 & 5.47 & 5.73 & 4.40 & 5.20 & 199.00 & 187.00 & 204.00 & 196.67 b-c \\
\hline G4- IFVN 567-Sel 2382 & 5.08 & 5.73 & 4.47 & 5.09 & 198.33 & 186.00 & 204.67 & $196.33 \mathrm{c}$ \\
\hline G5- IFVN 116-Sel 2461 & 5.75 & 5.87 & 5.27 & 5.63 & 198.33 & 185.67 & 205.00 & $196.33 \mathrm{c}$ \\
\hline G6- IFVN 562-Sel 2470 & 6.20 & 5.33 & 5.53 & 5.69 & 198.83 & 187.00 & 205.00 & 196.94 b-c \\
\hline G7- TARMAN-2002 & 5.71 & 5.33 & 5.33 & 5.46 & 201.67 & 186.67 & 206.33 & $198.22 \mathrm{a}$ \\
\hline Ortalama & $5.44 \mathrm{ab}$ & $5.68 \mathrm{a}$ & $5.05 \mathrm{~b}$ & 5.39 & $198.93 \mathrm{~b}$ & 186.81 & c 204.81 a & 196.85 \\
\hline $\mathrm{CV}(\%)$ & \multicolumn{4}{|c|}{7.43} & \multicolumn{4}{|c|}{0.56} \\
\hline \multicolumn{9}{|l|}{ LSD (0.05) } \\
\hline Y1llar & \multicolumn{4}{|c|}{$0.42 * *$} & \multicolumn{4}{|c|}{$0.71 * *$} \\
\hline Genotipler & \multicolumn{4}{|c|}{ ÖD } & \multicolumn{4}{|c|}{$1.07 * *$} \\
\hline Genotip $\times$ yll & \multicolumn{4}{|c|}{ ÖD } & \multicolumn{4}{|c|}{ ÖD } \\
\hline
\end{tabular}

+, aynı sütun içerisinde benzer harf grubu ile gösterilen ortalamalar, LSD (\% 5)'e göre farklı değildir; *, \% 5 düzeyinde önemli; **, \% 1 düzeyinde önemli; ÖD, önemli değildir.

Fizyolojik olum gün sayısı erkencilik açısından önem arz eden bir özelliktir. Araştırmada koca fiğ genotiplerinde kaydedilen fizyolojik olum gün sayısı değerleri 185.67 gün ile 206.33 gün arasında değişim göstermiştir. Üç yıllık genotip ortalamaları dikkate alındığında en düşük fizyolojik olum gün sayısına sahip genotipler G1, G4 ve G5 hatları olurken, en geç tohum olgunlaştıran genotipler ise G2 hatt1 ile Tarman-2002 çeşidi olmuştur (Çizelge 4). Balabanlı (1998)'nın (202.5-213.0 gün) koca fiğ genotiplerinde saptamış olduğu fizyolojik olum gün sayıları, araştırma bulgularımıza yakın bulunmuştur.

\section{GGE biplot grafikleri ile genotiplerin ve} incelenen özelliklerin değerlendirilmesi

Y1l ve y1l $\times$ genotip interaksiyonu grafiği için \% PC1 (\%34.83) (the first Principal Component - 1. Ana Bileşen) \% PC2 (the second Principal Component- 2. Ana Bileşen ) (\%57.76) değerleri toplamı \%92.59 olarak bulunmuştur. Bu yüksek yüzde oranına göre yıl, y1l $\times$ genotip interaksiyonun önem derecesinin yüksek olduğu söylenebilir. \% $\quad$ PC1 ve $\%$ PC2 değerleri toplamının yüksek olması GGE biplot grafiklerinde istenilen bir durum olup, bu toplam yüzde değeri yüksek olduğunda, araștırıcıların daha güvenli yorum yapabilecekleri bildirilmektedir (Yan ve ark., 2007; Fırıncıŏ̆lu ve ark., 2012; Sayar ve Han, 2015).

Tüm özellikler dikkate alındığında araştırmanın yürütüldüğü yıllar istatiksel olarak birbirlerinden farklı bulunmuştur. G1,G2 ve G4 hatları 2009-10 y1lında iyi performans gösterirken, G5 hattı 2010-11 yılında, G6 hattı ise 2008-09 yılında daha iyi performans gösterdiği söylenebilir (Şekil 1a). Şekil 1b'de yer alan Ranking biplot grafiğinde koca fiğ genotiplerinin sahip olduğu özellikleri koruma kararlılıkları gözükmektedir. İlgili şekil incelendiğinde ok ile gösterilen stabilite çizgisine en yakın olan G1, G2 ve G7 genotiplerinin sahip oldukları özellikleri koruma kararlılıkları yüksek genotipler oldukları söylenebilir. Şekil 1c incelendiğinde ise; incelenen tüm özellikler birlikte değerlendirildiğinde, bu özellikler için en ideal çevrenin en dar daireye yakın olan 2009-10 yılı olduğu söylenebilir.

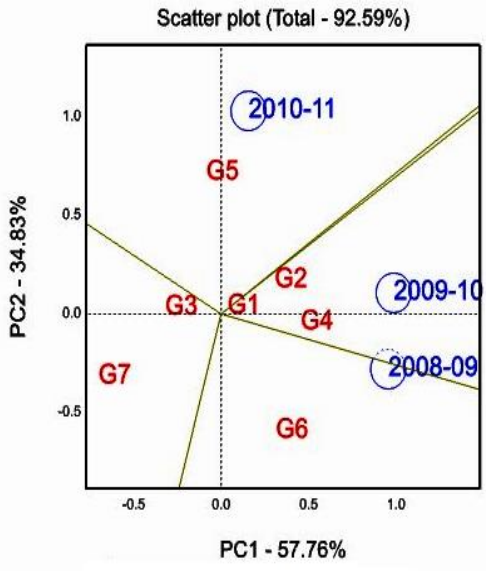

a

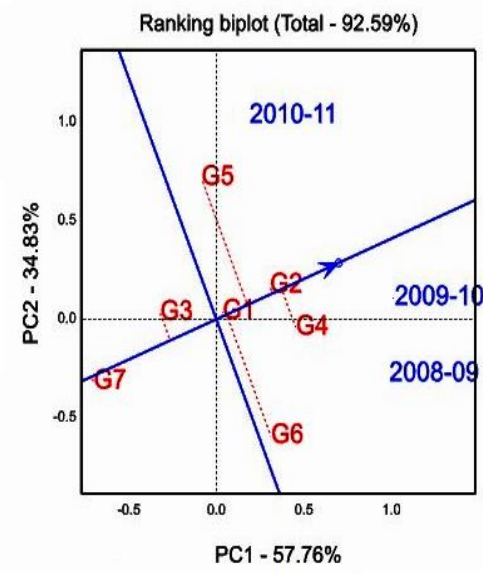

b

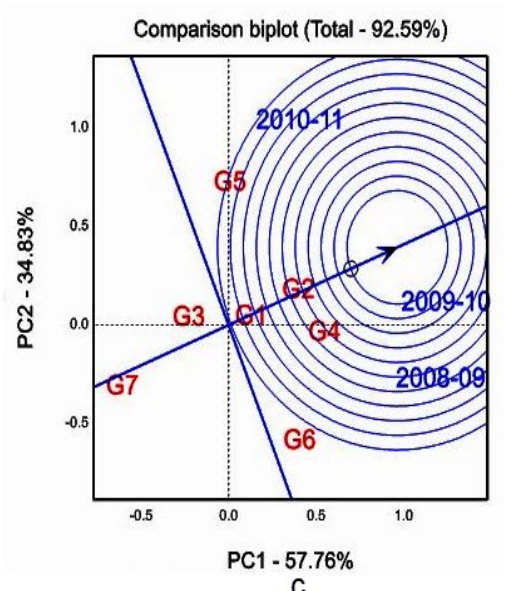

Şekil 1. Koca fiğ genotiplerinde yıl ve yıl $\times$ genotip interaksiyonlarını gösteren GGE Biplot grafikleri 
GGE Biplot yöntemi ile analize tabi tutulan koca fiğ genotipleri ve bu genotiplerde incelenen özelliklere ait genotip-özellik grafikleri Şekil 2'de gösterilmiştir. Biplot yöntemiyle yapılan analiz sonucuna göre, incelenen sekiz özellik üç gruba ayrılmıştır. En çok özelliğin yer aldığı grupta; tohum verimi (TV), biyolojik verim (BV), saman (kes) verimi (SV), bitkide bakla sayısı (BBS) ve hasat indeksi (HI) özellikleri yer almıştır. Aynı grupta yer alan bu özelliklerde vektörler arasındaki açının $90^{\circ}$ 'den küçük olduğu ve bu özellikler arasında olumlu ve önemli ilişki olduğu söylenebilir (Yan ve Kang, 2003; İlker ve ark., 2009; Sayar ve Han, 2015). Bulgularımızla benzer şekilde koca fiğde tohum verimi ile biyolojik verim, hasat indeksi ve bitkide bakla sayısı özellikleri arasında olumlu ve çok önemli korelasyon olduğu Türk ve ark. (2008) tarafindan da bildirilmektedir.

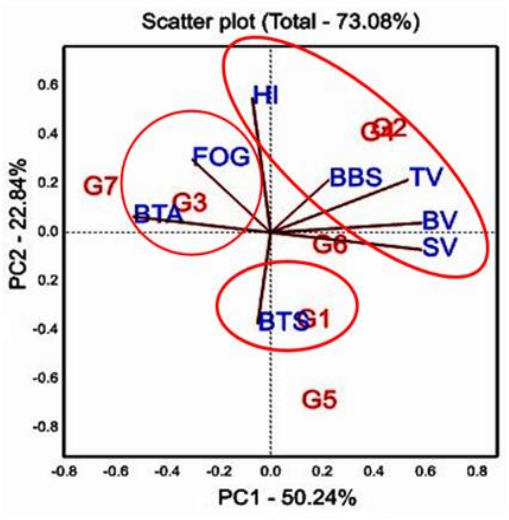

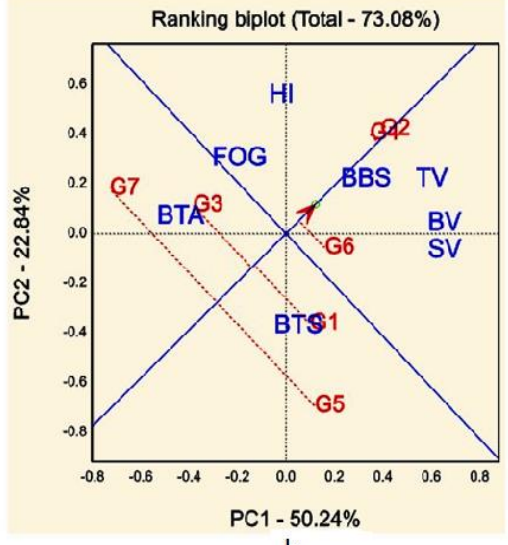

$\mathrm{b}$

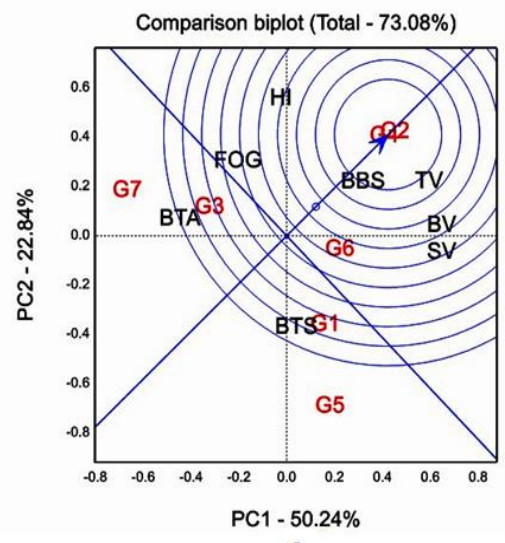

C
Şekil 2. Koca fiğ genotiplerinin genotip $\times$ özellik interaksiyonu ile özelliklerin birbirleriyle olan ilişkilerini gösteren biplot grafikleri (TV, tohum verimi; $\mathrm{BV}$, biyolojik verim; SV, saman (kes) verimi; HI, hasat indeksi, BTA, bin tane ağırlığı; BBS, bitkide bakla sayısı; BTS, baklada tane sayısı; FOG, fizyolojik olum gün sayıs1)

Araştırmamızda tohum veriminin de yer aldığı bu gruptaki 5 özellik bakımından G2 ve G4 genotipleri öne çıkmıştır. Fizyolojik olum gün sayısı (FOG) ve bin tane ağırlığı (BTA) özelliklerinin vektörleri birbirlerine yakın bulunmuş olup, aralarında olumlu ve önemli ilişki bulunan bu iki özellik ayrı bir grup oluşturmuş ve bu iki özellik bakımından G3 genotipi öne çıkmıştır. Diğer özelliklerden bağımsız tek başına üçüncü grubu oluşturan baklada tane sayısı (BTS) özelliği bakımından öne çıkan genotip G1 hattı olmuştur (Şekil 2a). Şekil 2 b'de okla gösterilen stabilite çizgisine en yakın, Şekil 2 c'de ise en dar ve merkezi dairede yer alan G2 ve G4 genotipleri sahip oldukları özellikleri koruma kararlılıkları en yüksek olan genotipler olduğu söylenebilir. $\mathrm{Bu}$ iki genotipin aksine stabilite çizgisine en uzak ve en dış dairede yer alan G5 ve G7 genotipleri ise interaksiyonları en yüksek ve kararlılıkları düşük olan genotipler olduğu söylenebilir.

\section{SONUÇ}

Araştırmada tohum verimi özelliğinin üç yıllık ortalamaları dikkate alındığında, araştırmada kullanılan ümitvar koca fiğ hatlarının tümü kontrol çeşidi Tarman2002 göre daha üstün bulunmuştur. Bununla beraber GGE Biplot analizi ile oluşturulan grafiklerde G2 ve G4 hatlarının tüm hatlardan daha yüksek tohum verimine sahip olduğu bu hatların aynı zamanda biyolojik verim, saman (kes) verimi, bitkide bakla sayısı ve hasat indeksi özellikleri bakımından da diğer genotiplerde daha üstün, ve sahip oldukları özellikleri koruma kararlılıklarının yüksek olduğu saptanmıştır.

\section{KAYNAKLAR}

Abd-El Moneim AM, Khair MA, Cocks PS 1990. Growth analysis, herbage and seed yield of certain forage legume species under rainfed Conditions, Journal of Agronomy and Crop Science, 164: 3441.

Abd-El Moneim AM 1992. Narbon vetch; A potential feed legume crop for dry areas in West Africa, Journal of Agronomy and Crop Science, 169 (5): 347-353.

Açıkgöz E 2001. Yem Bitkileri. Yenilenmiş 3. Baskı. Uludağ Üniversitesi Ziraat Fakültesi Tarla Bitkileri Bölümü. Uludağ Üniversitesi Vakfi Yayın No: 182. 584 s., Bursa.

Acikgoz E, Ustun A, Gul İ, Anlarsal AE, Tekeli AS, Nizam İ, Avcioglu R, Geren H, Cakmakcı S, Aydinoglu B, Yucel C, Avci M, Acar Z, Ayan I, Uzun A, Bilgili U, Sincik M, Yavuz M 2009. Genotype $\mathrm{x}$ environment interaction and stability analysis for dry matter and seed yield in field pea (Pisum sativum L.). Spanish Journal of Agricultural Research, 7(1): 96-106.

Anonim 2001. Tarımsal Değerleri Ölçme Denemeleri Teknik Talimatı (Baklagil Yem Bitkileri). T.C. Tarım ve Köyişleri Bakanlığı, Koruma ve Kontrol Genel Müdürlüğü, Tohumluk Tescil ve Sertifika. Merkezi Müdürlüğü, Ankara, 36 sayfa.

Balabanlı C 1998. Isparta ekolojik şartlarinda bazi koca fiğ hatlarinin (Vicia narbonensis L.) verim ve adaptasyonu. Tarla Bitkileri Merkez Araştırma Enstitüsü Dergisi, 7(2): 51-56.

Başbağ M., Gül İ 2004. Diyarbakır koşullarında koca fiğ (Vicia narbonensis L.) hatlarında bazı verim ve 
verim unsurlarının belirlenmesi, Harran Üniversitesi Ziraat Fakültesi Dergisi, 8(3/4): 45-50.

Başbağ M, Sayar MS, Aydın A, Hosgören H, Demirel R 2015. Some agronomical and quality traits in nine vetch (Vicia ssp.) species cultivated in Southeastern Anatolia, Turkey. Turkish Journal of Agricultural and Natural Sciences, 2(1): 69-77.

Bucak B 2008. Harran Ovası koşullarında bazı koca fiğ (Vicia narbonensis L.) hatlarının tohum veriminin belirlenmesi. Harran Üniversitesi Ziraat Fakültesi Dergisi, 12(2): 27-31.

Büyükburç U, İptaş S 2001. Tokat ekolojik koşullarında bazı koca fiğ (Vicia narbonensis L.) hatlarının verim ve verim öğeleri üzerinde bir araştırma. Turkish Journal of Agriculture and Forestry, 25: 79-88.

Çeçen S, Öten M, Erdurmuş C 2005. Batı Akdeniz sahil kuşağında bazı tek yıllık baklagil yem bitkilerinin ikinci ürün olarak değerlendirilmesi. Akdeniz Üniversitesi Ziraat Fakültesi Dergisi, 18(3): 331336.

Firıncıoğlu HK, Unal S, Pank Z, Beniwal SPS. 2012. Growth and development of narbon vetch (Vicia narbonensis L.) genotypes in the semi-arid central Turkey. Spanish Journal of Agricultural Research, 10(2): 430-442.

Gençkan MS 1983. Yem Bitkileri. Ege Üniv. Ziraat Fak. Yayın No: 467, Bornova. İzmir.

İlker E, Aykut Tonk F, Çaylak Ö, Tosun M, Özmen İ 2009. Assessment of genotype $\mathrm{x}$ environment interactions for grain yield in maize hybrids using AMMI and GGE biplot analyses. Turkish Journal of Field Crops 14(2): 123 - 135.

İptaş S, Büyükburç U, Yılmaz M 1996. Tokat ekolojik şartlarında yetiştirilen bazı koca fiğ (Vicia narbonensis L.) hatlarının verim ve adaptasyonu üzerine bir araştırma. Türkiye Çayır-Mera ve Yembitkileri Kongresi, 17-19 Haziran, Erzurum, 301-307.

İptaş S, Karadağ Y 2009. Determination of the yield and yield components of narbon vetch (Vicia narbonensis L.) lines grown in spring. 1st International Symposium on Sustainable Development, June 9-10 2009, Sarajevo, pp. 83-88.

Kalaycı M 1981. Eskişehir Zirai Araştırma Enstitüsü tarafından bugüne kadar yapılan nadas alanlarını azaltmaya yönelik çalışmalar, Kuru Tarım Alanları Sempozyumu, 28-30 Eylül, 195-206, Ankara.

Kendal E, Doğan Y 2015. Stability of a candidate and cultivars (Hordeum vulgare L.) by GGE biplot analysis of multi-environment yield trial in spring barley. Agriculture and Forestry, 61(4): 307-318.

Kendal E, Sayar MS 2016. The stability of some spring triticale genotypes using biplot analysis. Journal of Animal and Plant Sciences, 26(3): 754-765.

Kendal E, Aktaş H 2016. Investigation of genotypes by environment interaction using GGE Biplot analysis in barley. Oxidation Communications, 39 (3-I): 2433-2446.
Kendal E, Sayar MS, Tekdal S, Aktaş H, Karaman M 2016. Assessment of the impact of ecological factors on yield and quality parameters in triticale using GGE biplot and AMMI analysis. Pakistan Journal of Botany, 48(5): 1903-1913.

Kılıç H, Tekdal S, Kendal E, Aktaş H 2012. Augmented deneme desenine dayalı ileri kademe makarnalık buğday (Triticum turgidum ssp durum) hatlarının biplot analiz yöntemi ile değerlendirilmesi. Kahramanmaraş Sütçüimam Doğa Bilimleri Dergisi, 15(4): 18-25.

Manga İ, Acar Z. Ayan İ 1995. Baklagil Yembitkileri, O.M.Ü.Z.F. Yayınları, Yayın No; 7, 342, Samsun.

Nizam I, Orak A, Kamburoglu I, Cubuk MG, Moralar E 2011. Yield potentials of narbonne vetch (Vicia narbonensis L.) genotypes in different environmental conditions. Journal of food Agriculture and Environment, 9(1): 314-318.

Orak A, Nizam İ 2009. Genotypex environment interaction and stability analysis of some Narbonne vetch (Vicia narbonensis L.) genotypes. Agricultural science and technology, 1(4), 108-112.

Sabancı CO, Eğinlioğlu G. Özpınar H 1996. Menemen koşullarında koca fiğ (Vicia narnonensis L.) ve mürdümük (Lathyrus sativus L.) adaptasyonu üzerinde bir araştırma. Türkiye 3. Çayır-Mera ve Yem-Bitkileri Kongresi, 17-19 Haziran, Erzurum, 287-292.

Sabancı CO, Özpınar H, Eğinlioğlu G 1998. Bazı yem bitkilerinin Menemen koşullarına adaptasyonları üzerine araştırmalar. I. koca fiğ (Vicia narbonensis L.). Anadolu, J. of AARI, 8 (2):42 - 50.

Sağlamtimur T, Tansı V, Baytekin H 1988. Yembitkileri Yetiştirme. Çukurova Üniversitesi Ziraat Fakültesi, Ders Kitabı No: 74, Adana, 94 sayfa.

SAS Institute 2002. JMP Statistics. Cary, NC, USA: SAS Institute, Inc. pp.70

Sayar MS, Anlarsal AE, Basbag M 2013. Genotypeenvironment interactions and stability analysis for dry-matter yield and seed yield in Hungarian vetch (Vicia pannonica CRANTZ.). Turkish Journal of Field Crops, 18(2): 238-246.

Sayar MS, Han Y 2015. Mürdümük (Lathyrus sativus L.) Hatlarının Tohum Verimi ve Verim Komponentlerinin Belirlenmesi ve GGE Biplot Analiz Yöntemiyle Değerlendirilmesi. Tarım Bilimleri Dergisi- Journal of Agricultural Sciences, 21(1): 78-92.

Sayar MS, Han Y, Başbağ M, Gül İ, Polat T 2015. Rangeland improvement and management studies in Southeastern Anatolia Region of Turkey. Pakistan Journal of Agricultural Sciences, 52(1): 918.

Sayar MS, Han Y 2016. Forage yield performance of forage pea (Pisum sativum spp. arvense L.) genotypes and assessments using GGE biplot analysis. Journal of Agricultural Science and Technology, 18 (6):1621-1634. 
Steel GD, Torrie JH 1980. Principles and Procedures of Statistics: A Biometrical Approach. 2. ed. New York: McGraw-Hill Publ. Company.

Türk M, Bayram G, Budaklı E, Çelik N 2004. Bursa ekolojik koşullarında yetiştirilen koca fiğ (Vicia narbonensis L.) hatlarının verim ve adaptasyonu üzerinde bir araştırma. Süleyman Demirel Üniversitesi Fen Bilimleri Enstitüsü Dergisi, 8(1): 21-25.

Türk M, Çelik N, Bayram G, Budaklı E 2008. Relationships between seed yield and yield components in narbon bean (Vicia narbonensis L.) by path analysis. Bangladesh Journal of Botany, 37(1): 27-32.

Uzunmehmetoğlu B, Kendir H 2006. Yazlık ve kışlık ekimin koca fiğ (Vicia narbonensis L.) hatlarında tane verimine etkileri. Ankara Üniversitesi Ziraat Fakültesi Tarım Bilimleri Dergisi, 12(3): 294-300.
VSN International 2011. GenStat for Windows 14th Edition. VSN International, Hemel Hempstead, UK. Web page: GenStat.co.uk

Yan W, Hunt LA, Sheng Q, Szlavnics Z 2000. Cultivar evaluation and mega-environment investigation based on the GGE biplot. Crop Science, 40: 597605.

Yan W, Kang MS 2003. GGE Biplot Analysis: A Graphical Tool for Breeders, Geneticists, and Agronomists. CRC Press, Boca Raton, FL, pp.288.

Yan W, Tinker NA 2006. Biplot analysis of multienvironment trial data: Principles and applications. Canadian Journal of Plant Science, 86: 623-645.

Yan W, Kang MS, Manjit B, Woodsc S, Corneliusd PL 2007. GGE Biplot vs. AMMI Analysis of Genotype-by-Environment Data. Crop Science, 47( 2): 643-653. 